\title{
Imidazole inhibits autophagy flux by blocking autophagic degradation and triggers apoptosis via increasing FoxO3a-Bim expression
}

\author{
ZHENXING LIU ${ }^{1}$, YINGZHENG WANG ${ }^{1}$, SHUAN ZHAO ${ }^{1}$, JINGYOU ZHANG ${ }^{2}$, YI WU ${ }^{1}$ and SHENMING ZENG ${ }^{1}$ \\ ${ }^{1}$ Laboratory of Animal Embryonic Biotechnology, College of Animal Science and Technology, China Agricultural University, \\ Beijing 100193; ${ }^{2}$ Reproduction and Breeding Research Center, Animal Husbandry and Veterinary 9th Research Institute, \\ Heilongjiang Academy of Agricultural and Reclamation Science, Harbin 150006, P.R. China
}

Received September 10, 2014; Accepted October 13, 2014

DOI: 10.3892/ijo.2014.2771

\begin{abstract}
Imidazole, an organic alkaloid, is an important pharmacophore in drug discovery. Anti-neoplastic potential of imidazole derivatives has been documented in several studies; however, mechanisms by which tumor cells respond to these stimuli remain to be elucidated. Autophagy and apoptosis have key roles in tumorigenesis and tumor treatment. In this study, we systematically examined autophagic events induced by imidazole in HEC-1B cells. Accumulation of autophagic vacuoles in imidazole-treated cells was verified by conversion of LC3 protein, as well as confocal and transmission electron microscopy. Furthermore, imidazole blocked autophagic degradation by impairing maturation of autophagosomes into autolysosomes. Concurrently, imidazole treatment induced apoptosis in HEC-1B cells, accompanied by activation of caspase 9 and 3. The proapoptotic effect was mediated by increased Bim expression. Moreover, imidazole upregulated the protein level of Foxo3a and induced its increased nuclear localisation. In addition, siRNA-mediated silencing of FoxO3a effectively attenuated imidazole-induced Bim upregulation and cell death, indicating direct involvement of this pathway in the imidazole-induced apoptosis. Taken together, our data provided a molecular link between imidazoles and anticancer therapies; understanding of these properties of imidazole is essential for development of effective cancer therapeutics using imidazoles.
\end{abstract}

\section{Introduction}

Imidazole, an organic compound with the formula $\mathrm{C}_{3} \mathrm{H}_{4} \mathrm{~N}_{2}$, is classified as an alkaloid. It is incorporated into many impor-

Correspondence to: Professor Shenming Zeng, Laboratory of Animal Embryonic Biotechnology, College of Animal Science and Technology, China Agricultural University, Beijing 100193, P.R. China E-mail: zengsm@cau.edu.cn

Key words: imidazole, LC3-II, autophagy, apoptosis, Bim, FoxO3a tant biological molecules; the most widespread is the amino acid histidine, which has an imidazole side-chain. Imidazole is an important pharmacophore in drug discovery. Its derivatives have diverse pharmaceutical effects, including histamine-H3 antagonist (1), anti-inflammatory (2), gastroprotective (3), and antioxidant (4). Importantly, several imidazole derivatives had anticancer activity against a variety of malignant cells. Misonidazole can sensitize hypoxic tumor cells to radiation therapy and directly kill hypoxic cancer cells $(5,6)$. Furthermore, N-fused imidazoles inhibited catalytic activity of topoisomerase II $\alpha$ and induced apoptosis at the G1/S phase in kidney and breast cancer cell lines (7). Temozolomide is an alkylating drug that induces apoptosis and senescence in glioma cells (8). Due to their therapeutic significance, the mechanism responsible for the chemotherapeutic effects of imidazoles has received considerable interest for future development of novel anticancer drugs.

Autophagy is an evolutionarily conserved process through which protein aggregates, damaged organelles and intracellular pathogens are sequestered by autophagosomes and degraded by lysosomes, resulting in nutrient recycling and energy generation (9), enabling cells to sustain metabolism under conditions of starvation or growth factor withdrawal. Autophagy has been linked to a variety of pathological processes such as neuronal degeneration, pathogen infection, aging and tumorigenesis (10). It is noteworthy that autophagy may facilitate survival of tumor cells under stress conditions, e.g., nutrient limitation, hypoxia and antineoplastic treatment. Furthermore, inhibition of autophagy promotes cancer cell death (11-13) and potentiates various anticancer therapies (14-17). The critical role of autophagy in regulating cell survival and cell death makes it be a potential therapeutic target for tumor treatment. Autophagosome clearance depends on its fusion with a lysosome (18). As a weak base, imidazole can enter lysosomes and induce cytoplasmic vacuolization (19). However, the effects of imidazole on autophagy are still poorly documented.

Many anticancer treatments, including chemotherapeutic drugs and radiation therapy, actually induce apoptosis and thereby utilize apoptotic machinery to kill cancer cells $(20,21)$. The Bcl-2-homology domain 3 only (BH3-only) proteins are essential for initiation of various physiological apoptotic situ- 
ations, including developmentally programmed cell death and stress-induced apoptosis $(22,23)$. Pro-apoptotic protein Bim (Bcl-2-interacting modulator of cell death) is one of these $\mathrm{BH} 3$-only proteins. Alternative splicing generates three Bim isoforms, including $\mathrm{Bim}_{\mathrm{S}}, \mathrm{Bim}_{\mathrm{L}}$ and $\mathrm{Bim}_{\mathrm{EL}}$, with different variations in pro-apoptotic activities (24). In a variety of cell types, its upregulation can induce apoptosis via promoting release of cytochrome $c$, which consequentially induces formation of the apoptosome and the activation of caspases $(24,25)$. Moreover, Bim plays a key role in the anoikis of many tumor cells, such as lung cancer, breast cancer, osteosarcoma, and melanoma (26-28). Thus, it has attracted increasing attention as a plausible target for cancer treatment. It has been reported that imidazole can induce cell apoptosis (29). However, the mechanisms by which imidazole induces apoptosis remain largely unknown.

In the present study, we carefully evaluated the autophagic and apoptotic events induced by imidazole in human endometrial adenocarcinoma cell line (HEC-1B). By systematically studying imidazole induced alterations in autophagy, we were able to characterize one potential autophagy modulator and explore the roles of autophagy related drugs in cancer therapy. Simultaneously, we also focused this study on the FoxO3a regulation of Bim expression after imidazole treatment, in an attempt to gain further mechanistic insights on the molecular pathways leading to imidazole-induced apoptosis.

\section{Materials and methods}

Chemicals and antibodies. All chemicals were purchased from Sigma-Aldrich (St. Louis, MO, USA), unless otherwise indicated. The LC3 antibody was obtained from Sigma-Aldrich. Antibodies against Bim, FoxO3a, cleaved-caspase 9, cleavedcaspase 3 and p62 were purchased from Cell Signaling Technology (Danvers, MA, USA). Antibodies against GFP and $\beta$-actin were obtained from Abmart (Shanghai, China). The LAMP-1 antibody was obtained from Abcam (Cambridge, UK). The HRP-conjugated goat anti-rabbit or anti-mouse secondary antibodies were purchased from Santa Cruz Biotechnology (Santa Cruz, CA, USA).

Cell culture. The HEC-1B cells were purchased from the Institute of Basic Medical Sciences, Chinese Academy of Medical Sciences (Beijing, China), MDA-MB-435S and 293T cells were obtained from Peking University Laboratory Animal Center (Beijing, China). Cells were cultured in Dulbecco's modified Eagle's medium: nutrient mixture F-12 (DMEM/F12) supplemented with $10 \%$ fetal bovine serum (Invitrogen, Carlsbad, CA, USA) and $100 \mathrm{U} / \mathrm{ml}$ penicillin and $100 \mu \mathrm{g} / \mathrm{ml}$ streptomycin. For imidazole treatment experiments, imidazole dissolved in the phosphate-buffered saline (PBS; Invitrogen) was added into culture medium (various doses and intervals). The HEC-1B cells were treated with $50 \mathrm{nM}$ rapamycin for $12 \mathrm{~h}$ or incubated in Earle's balanced salt solution (EBSS; Invitrogen) for $1 \mathrm{~h}$ to induce autophagy. Bafilomycin A1 (Baf A1), a proton-ATPase inhibitor, was used to inhibit the autophagic flux.

Live-cell imaging. The HEC-1B cells were treated with or without $5 \mathrm{mM}$ imidazole for $6 \mathrm{~h}$, and then examined for vacuolization under an inverted light microscope (x400 magnification; Olympus, Tokyo, Japan). For acridine orange (AO) staining, cells grown on coverslips were treated with vehicle or $5 \mathrm{mM}$ imidazole for $6 \mathrm{~h}$, and then stained with the $\mathrm{pH}$-sensitive fluorescent dye AO $\left(5 \mu \mathrm{g} / \mathrm{ml}\right.$ in PBS) at $37^{\circ} \mathrm{C}$ for $10 \mathrm{~min}$. After washing twice with PBS, samples were viewed under a confocal fluorescence imaging microscope (Nikon D-Eclipse C1; Nikon, Tokyo, Japan) equipped with an 60x oil immersion objective, and confocal images were acquired using EZ-C1 software (version 3.90; Nikon).

Immunofluorescence. The HEC-1B cells were seeded on glass coverslips and then treated with vehicle or $5 \mathrm{mM}$ imidazole for $6 \mathrm{~h}$, then fixed in $4 \%$ paraformaldehyde and permeabilized with $0.3 \%$ Triton X-100 in PBS. For blockage of non-specific binding sites, cells were incubated with $5 \%$ normal goat serum in PBS for $1 \mathrm{~h}$ at room temperature. The anti-LAMP-1 antibody (1:100 dilution in the PBS containing 5\% bovine serum albumin) was incubated with treated cells at $4^{\circ} \mathrm{C}$ overnight. After washing three times, cells were incubated for $1 \mathrm{~h}$ with goat anti-rabbit secondary antibody conjugated to TRITC (Santa Cruz Biotechnology). Counterstaining of nuclei was done with Hoechst 33342 (Sigma-Aldrich). Cells were imaged under the confocal microscope and image analysis was performed using EZ-C1 FreeViewer software (Nikon).

Examination of AVs by transmission electronic microscopy. The HEC-1B cells, with or without imidazole treatment, were fixed in $2.5 \%$ glutaraldehyde in $0.1 \mathrm{M}$ sodium cacodylate buffer at $4{ }^{\circ} \mathrm{C}$ overnight and postfixed with $1 \%$ osmium tetroxide in $0.1 \mathrm{M}$ sodium cacodylate buffer for $1 \mathrm{~h}$ at room temperature. After fixation, cells were dehydrated in a gradient of $30-100 \%$ acetone and embedded in SPI-Pon 812 resin. Ultrathin sections were obtained using a microtome (Leica UC6i; Leica Microsystems, Wetzlar, Germany). After staining with lead citrate/uranyl acetate, sections were examined under a transmission electron microscope (JEM-1230; JEOL, Japan) at $80 \mathrm{kV}$.

Plasmids construction and transfection. The full length of human microtubule-associated protein 1 light chain 3 (LC3; GenBank accession no. NM_022818.4) was amplified by PCR using forward (5'-TTCTCGAGCTATGCCGTCGGAGA AGA-3') and reverse (5'-AAGGATCCTTAC ACTGACAATTT CATCC-3') primers, and the HEC-1B cDNA library as template. The PCR fragment of LC3 digested with XhoI and BamHI (New England Biolabs, Ipswich, MA, USA) was cloned into pEGFP-C1 plasmid (Clontech, Palo Alto, CA, USA) for generation of enhanced green fluorescent protein-LC3 (EGFP-LC3) transfection vector. A plasmid that encoded human FoxO3a (GenBank accession no. NM_001455.3) tagged with EGFP (FoxO3a-EGFP) was constructed into pEGFP-N1 plasmid (Clontech) at XhoI and BamHI sites using the same cDNA library and specific forward (5'-AACT CGAGATGGCAGAGGCACCGGCT-3') and reverse (5'-TTG GATCCTTGCCTGGCACCCAGCTCTG-3') primers in PCR. All constructs were verified by sequencing. The mRFPGFP-LC3 expression plasmid was a generous gift from Dr Hou (Key Laboratory of Zoonosis, College of Veterinary Medicine, China Agricultural University, Beijing, China). For transient 
transfection, all vectors described above were transfected to the cells using Lipofectamine 2000 (Invitrogen) according to the manufacturer's protocols. Twenty-four hours after transfection, cells were treated with vehicle or imidazole for indicated intervals and viewed with confocal fluorescence microscopy.

Cell viability assay. The HEC-1B cells were seeded in 96-well plates at a density of $1 \times 10^{4}$ cells per well. After imidazole treatment, cell viability was assessed using 3-(4,5-dimethylthiazol-2-yl)-2,5-diphenyl tetrazolium bromide (MTT) dye (Sigma-Aldrich) absorbance and expressed as the percentage of non-treated cells. The MTT assay was done as described (30). Briefly, after exposure of cells to imidazole, culture media were changed by serum-free culture media. Then, MTT dissolved in PBS was added to each well for $4 \mathrm{~h}$ at $37^{\circ} \mathrm{C}$. After this interval, the culture media containing MTT were discarded and DMSO was added to each well, dissolving the precipitate. The optical density was measured at $570 \mathrm{~nm}$ spectral wavelength using a microplate reader (Bio-Rad, Hercules, CA, USA).

Reverse transcriptase-polymerase chain reaction (RT-PCR). After imidazole treatment, total RNA was obtained with a TRIzol reagent (Invitrogen) and quantified by spectrophotometry (Nanodrop 1000; Thermo Scientific, Waltham, MA, USA). RevertAid First Strand cDNA Synthesis kit (K1622; Thermo Scientific) was used to reverse-transcribe RNA into cDNA. PCR was performed using the Veriti 96-well thermal cycler (Applied Biosystems, Carlsbad, CA, USA) for 30 cycles. Primer sequences were as follows: Bim, 5'-ATGGCAAA GCAACCTTCTGA-3' (forward) and 5'-CGCATATCTGCA GGTTCAGCC-3' (reverse); GAPDH, 5'-CAAGGTCATCC ATGACAACTTTG-3' (forward) and 5'-GTCCACCACCCT GTTGCTGTAG-3' (reverse).

Gene silencing with siRNA. The HEC-1B cells were grown to $50-60 \%$ confluence in 6 -well cell culture plates and then transfected with FoxO3a small interfering RNA (siRNA) (GenePharma, Shanghai, China) using Lipofectamine 2000, according to the manufacturer's protocols. The plates were incubated at $37^{\circ} \mathrm{C}$ in a $\mathrm{CO}_{2}$ incubator for $6 \mathrm{~h}$, and mixtures were replaced with fresh complete medium and were incubated for an additional $24 \mathrm{~h}$ before silencing efficiency was measured (western blotting). A non-targeting siRNA was used as a negative control.

Western blot analysis. Cells lysates were prepared by extracting proteins with RIPA buffer (Sigma-Aldrich) containing protease cocktail inhibitor (Roche, Basel, Switzerland). Equal amounts of protein samples $(20 \mu \mathrm{g})$ were subjected to sodium dodecyl sulfate-polyacrylamide gel electrophoresis and transferred to a nitrocellulose membrane (Millipore, Billerica, MA, USA). After blocking with 5\% non-fat milk in Tris-buffered saline containing $0.1 \%$ Tween-20 (TBST), the membrane was incubated with primary antibodies diluted in blocking solution $(1: 1,000)$ at $4^{\circ} \mathrm{C}$ overnight. After washing with TBST, the membrane was incubated for an additional $1 \mathrm{~h}$ with the appropriate secondary antibodies conjugated to horseradish peroxidase at a dilution of 1:5,000. The protein bands were visualized using an enhanced chemiluminescence detection system (GE Healthcare, Little Chalfont, Buckinghamshire, UK). Images of western blotting were processed using Image J software (Wayne Rasband, NIH, Bethesda, MD, USA).

Statistical analyses. Data were presented as mean \pm standard deviation of at least three independent experiments. Statistical significance was analyzed using the Student's t-test for comparison between the means or one-way analysis of variance with post hoc Dunnett's test (SAS version 9.1; SAS Institute Inc., Cary, NC, USA). Differences were considered statistically significant when $\mathrm{P}<0.05$.

\section{Results}

Imidazole induced cytoplasmic vacuolization and accumulation of AVs in HEC-1B cells. The HEC-1B cells had large vacuoles in their cytoplasm after addition of $5 \mathrm{mM}$ imidazole (Fig. 1A, top row). Staining the imidazole-treated cells with AO was consistent with an increase of the acidic organelle (Fig. 1A, middle row). Further, lysosomes were stained using lysosome associated membrane protein (LAMP)-1 directed antibody, which revealed an increase in number and in size of lysosomes following imidazole treatment (Fig. 1A). Furthermore, imidazole treatment resulted in a significant increase in the abundance of LC3-II in a dose- and time-dependent manner (Fig. 1B). Two additional cell lines, MDA-MB-435S and 293T, displayed a similar increase in the abundance of LC3-II following treatment with imidazole (Fig. 1C). These results suggested that the number of autophagosome increased in response to imidazole. This observation was further supported by TEM analyses showing that the number of autophagic vacuoles (AVs) was markedly increased in cytoplasm following treatment with imidazole (Fig. 1D). Taken together, these data indicated that the accumulation of AVs was induced in imidazole-treated cells.

Imidazole blocked autophagic degradation. Autophagy flux was monitored using EGFP-LC3 in HEC-1B cells treated with imidazole. The addition of imidazole significantly increased the number of EGFP-LC3 puncta (Fig. 2A) and in the abundance of EGFP-LC3-II protein (Fig. 2B). These results further indicated the accumulation of AVs in response to imidazole. Based on immunoblot analysis of the free EGFP fragment, there was a time-dependent reduction in imidazole-treated cells (Fig. 2B). In contrast, induction of autophagy in response to EBSS increased free EGFP fragment. Furthermore, the p62 levels were markedly increased in response to imidazole treatment (Fig. 2C). In addition, dual treatment with imidazole and Baf A1 did not result in any significant change in the abundance of LC3-II, compared to Baf A1 treatment alone (Fig. 2D), suggesting that imidazole functions were similar to Baf A1 by blocking autophagic flux. Therefore, we attributed the imidazole-induced accumulation of AVs to the blockage of autophagic degradation rather than increased induction of autophagy.

Imidazole impaired the maturation of autophagosome into autolysosome. To address whether imidazole treatment affects maturation of autophagosome, autolysosome formation was measured by an mRFP-GFP-LC3 tandem construct. The low 

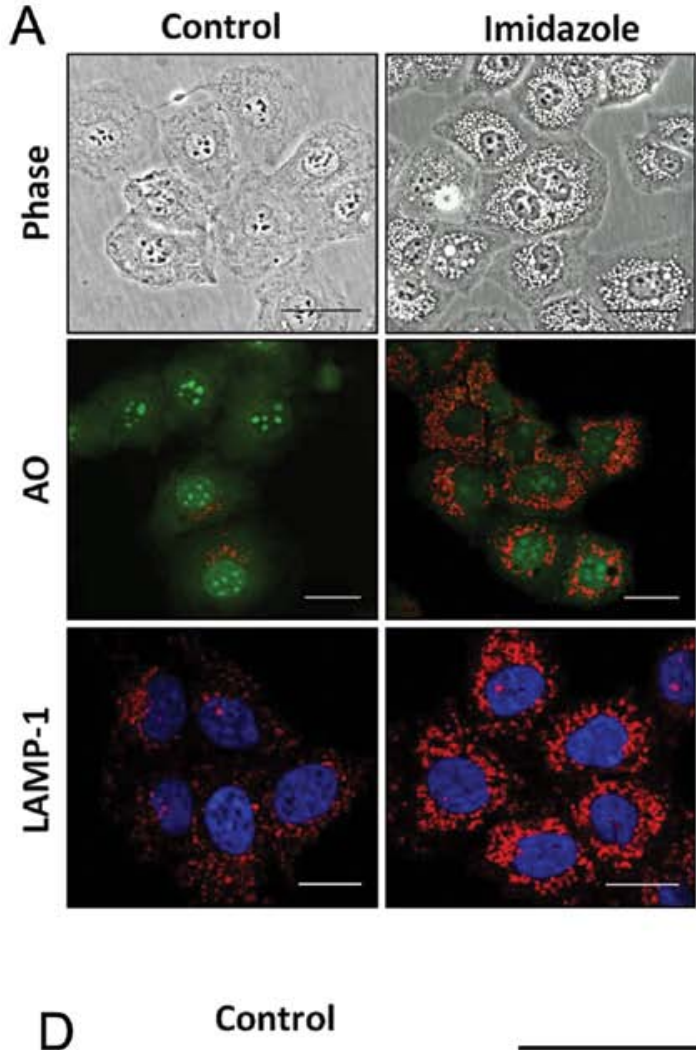

D
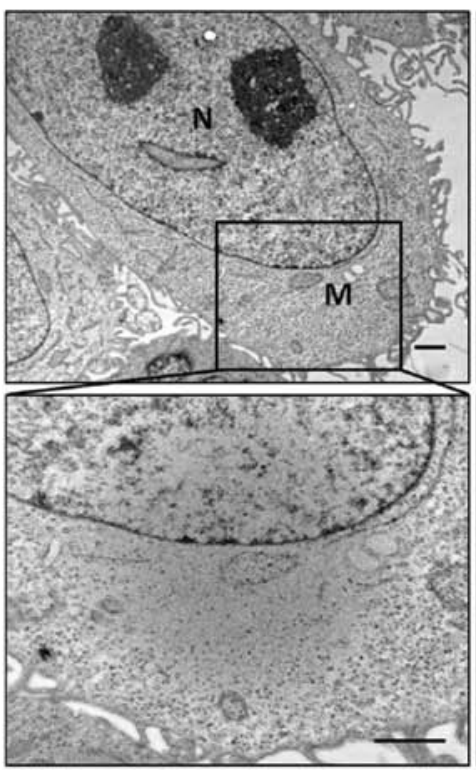

B

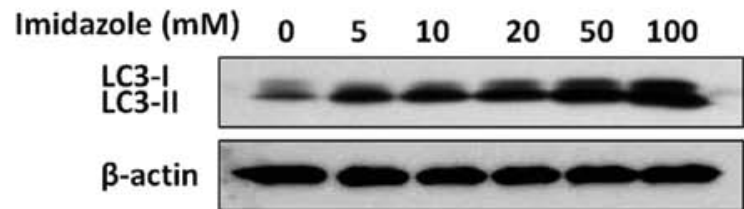

Time (12 h)

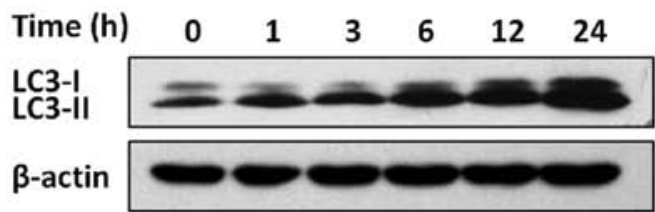

Imidazole (5 mM)

C

Imidazole (5 mM)

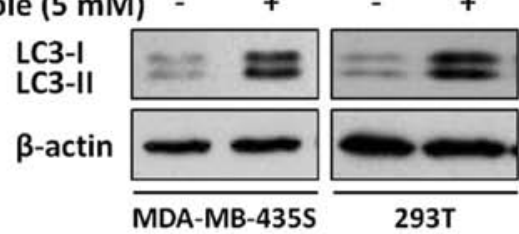

Imidazole (5 mM)

$1 \mathrm{~h}$
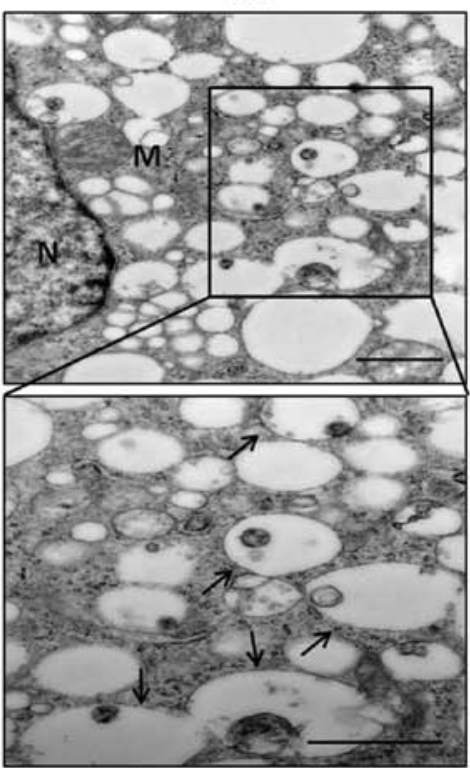

$3 \mathbf{h}$
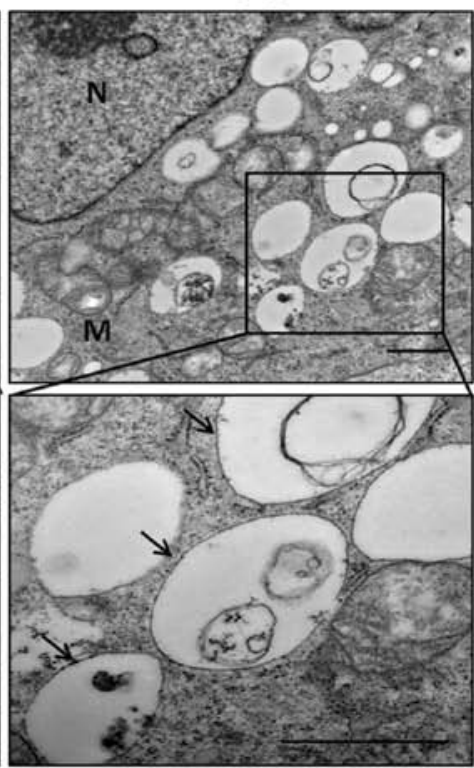

Figure 1. Imidazole treatment induces cellular vacuolization and accumulation of AVs. (A) Vacuoles formation in imidazole-treated cells. The HEC-1B cells with or without $5 \mathrm{mM}$ imidazole treatment for $6 \mathrm{~h}$ were observed (phase-contrast microscopy, $\mathrm{x} 400$ magnification). The distribution of acidic organelles was examined by AO staining and visualized with various channels using confocal microscopy (x400 magnification). Cells were fixed, permeabilized and analyzed using polyclonal antibody against LAMP-1 to recognize lysosomes. Hoechst staining was used to identify nuclei. AO, acridine orange. Bars, $20 \mu \mathrm{m}$. (B) Imidazole increased accumulation of LC3-II in a dose- and time-dependent manner. Cells that were treated with increasing amounts of imidazole or in a certain concentration of imidazole for indicated intervals were examined by western blotting with anti-LC 3 antibody, and $\beta$-actin was used as loading control. (C) MDA-MB-435S and 293T cell lines were treated with or without imidazole for $12 \mathrm{~h}$, and the conversion of LC3-I to LC3-II was monitored by western blotting. (D) Ultrastructures of HEC-1B cells with or without imidazole treatment. Representative TEM images are presented at x12,000 or x 25,000 magnification. $\mathrm{N}$, nucleus; M, mitochondrion; arrows indicate AVs. Bars, $1 \mu \mathrm{m}$. Comparable results were obtained in at least three separate experiments.

pH inside the lysosome quenched the fluorescent signal of GFP; however, RFP has more stable fluorescence in acidic compartments. Thus, autophagosomes and autolysosomes are labeled with yellow (mRFP and GFP) and red (mRFP only) signals, respectively (31). In the present study, imidazole considerably increased the yellow puncta numbers without a concomitant increase in red puncta (Fig. 3). In contrast, both yellow and red puncta were increased in cells treated with rapamycin, a 

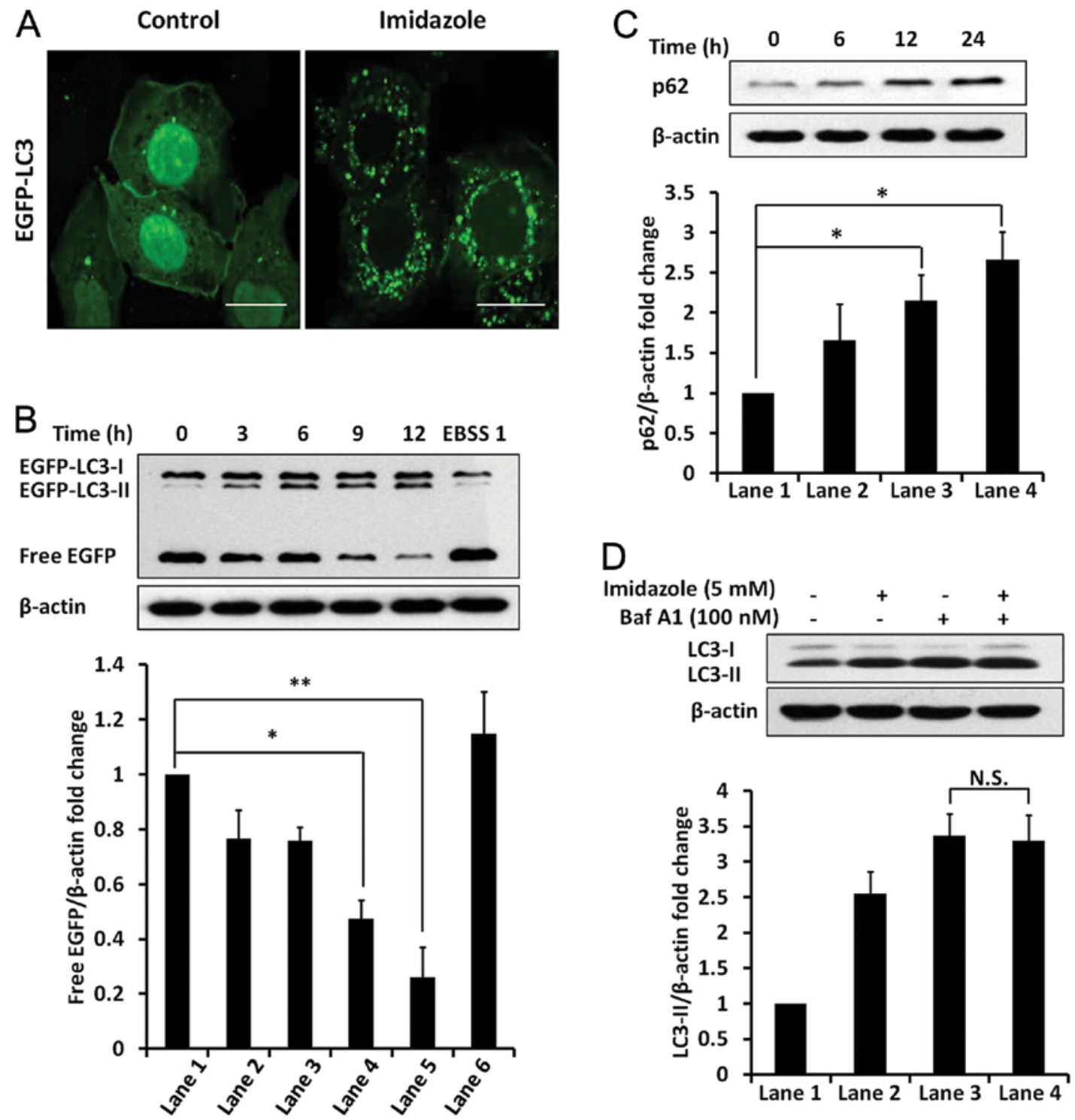

Figure 2. Autophagic flux is inhibited by imidazole treatment. (A) Subcellular distributions of EGFP-LC3. The HEC-1B cells were transfected with the EGFP-LC3 vectors and cultured in complete medium (with or without $5 \mathrm{mM}$ imidazole) for $12 \mathrm{~h}$. The fluorescent signals of EGFP-LC3 were sequentially acquired by confocal microscopy (x600 magnification). Bars, $20 \mu \mathrm{m}$. (B) Conversion of EGFP-LC3 in imidazole-treated cells. Cells transfected with EGFP-LC3 were cultured in EBSS nutrient starvation medium or complete medium, with or without $5 \mathrm{mM}$ imidazole, for indicated intervals. Corresponding changes in EGFP-LC3 and free EGFP were monitored by western blotting with an anti-GFP antibody, and $\beta$-actin was used as loading control. (C) Cells were treated with imidazole for indicated intervals, and western blotting was used to analyze the abundance of p62 protein. (D) Conversion of LC3-I to LC3-II was assayed in the imidazole-treated cells with or without Baf A1. The HEC-1B cells that were treated with or without imidazole for $4 \mathrm{~h}$ were cultured in complete medium (with or without Baf A1) for $2 \mathrm{~h}$. Western blotting was used to monitor LC3-II protein levels. Baf A1, bafilomycin A1. All data for comparison of the intensities of western blotting were analyzed and are presented as means $\pm \mathrm{SD}$ of three independent experiments. N.S., not significant; ${ }^{*} \mathrm{P}<0.05,{ }^{* *} \mathrm{P}<0.01$.

known autophagy inductor. We inferred that autophagosome maturation into autolysosome was blocked in the presence of imidazole.

Effect of imidazole treatment on cell viability. Imidazole reduced $\mathrm{HEC}-1 \mathrm{~B}$ cell viability in a dose- and time-dependent manner (Fig. 4A). Based on western blot analysis, both cleaved-caspase 9 and cleaved-caspase 3 levels increased after imidazole treatment (Fig. 4B). Therefore, imidazole treatment induced intrinsic apoptotic cell death in HEC-1B cells.

Imidazole treatment increased Bim expression. Bim $\mathrm{EL}_{\mathrm{EL}}$ and $\mathrm{Bim}_{\mathrm{L}}$ protein levels were dramatically increased after imidazole treatment (Fig. 5A). Western blotting results were consistent with RT-PCR data (Fig. 5A), demonstrating that imidazole treatment increased Bim expression, both at transcriptional and translational levels. Furthermore, two additional cell lines, MDA-MB-435S and 293T, displayed a similar increase in the abundance of $\mathrm{Bim}_{\mathrm{EL}}$ following treatment with imidazole (Fig. 5B). In addition, LC3-II levels were markedly increased in response to $\mathrm{CQ}$ or $\mathrm{Baf} \mathrm{A} 1$; however, the $\mathrm{Bim}_{\mathrm{EL}}$ levels were not obviously affected by CQ or Baf A1 treatment (Fig. 5C). Taken together, we concluded that imidazole-induced Bim upregulation was independent of the blockage of autophagic degradation.

FoxO3a was involved in regulation of Bim expression in respone to imidazole. Imidazole treatment increased FoxO3a 


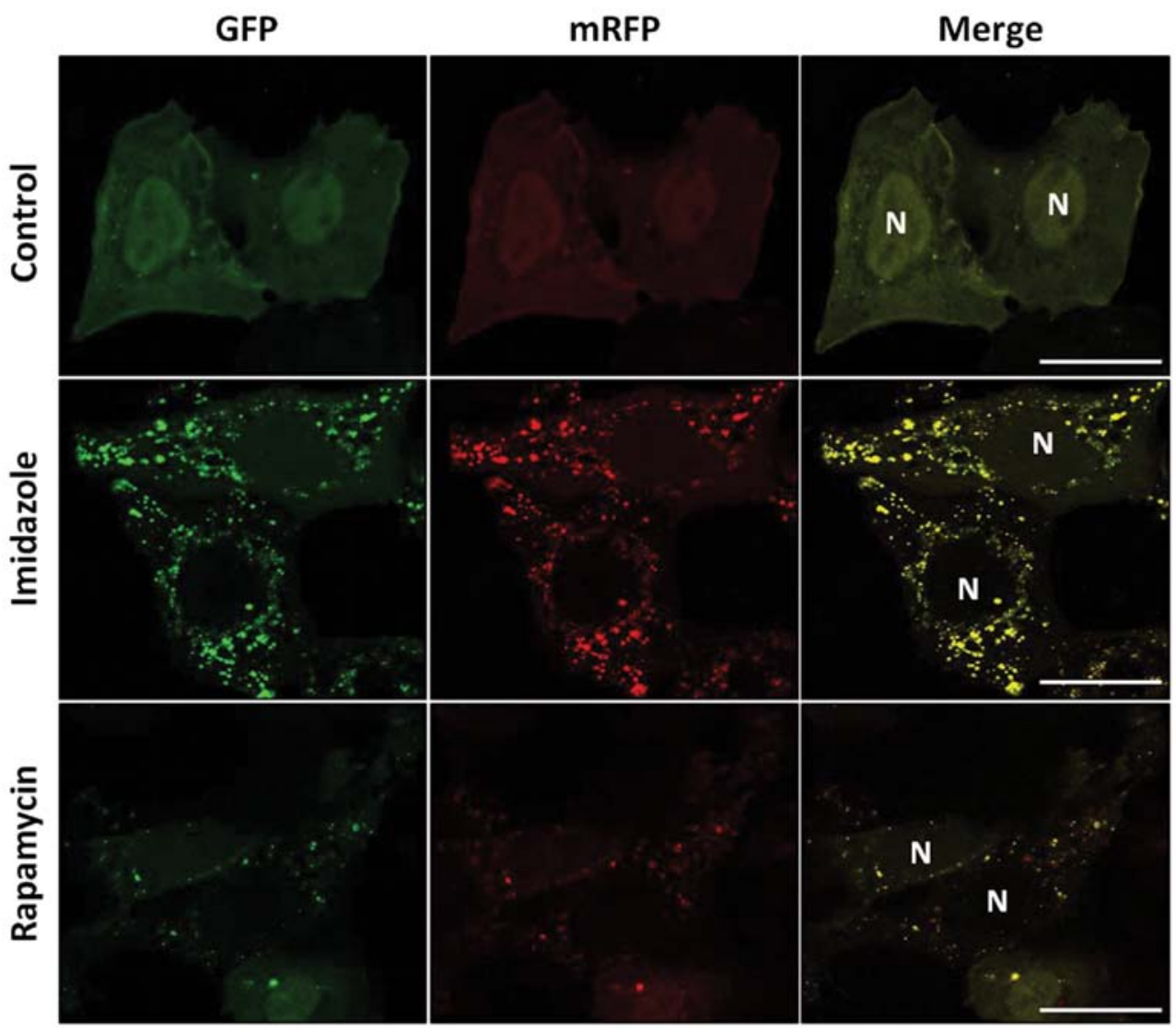

Figure 3. Autophagosome maturation is blocked by imidazole treatment. The HEC-1B cells were transiently transfected with the mRFP-GFP-LC3 vectors and cultured in complete medium, with or without $5 \mathrm{mM}$ imidazole, for $12 \mathrm{~h}$. Cells treated with rapamycin $(50 \mathrm{nM}, 12 \mathrm{~h})$ were used as a positive control Cells expressing mRFP-GFP-LC3 were fixed and scanned with various channels using confocal microscopy (x600 magnification). Yellow and red punctae represented autophagosomes and autolysosomes, respectively. Representative confocal images are shown. Bars, $20 \mu \mathrm{m}$. Comparable results were obtained in three independent experiments.
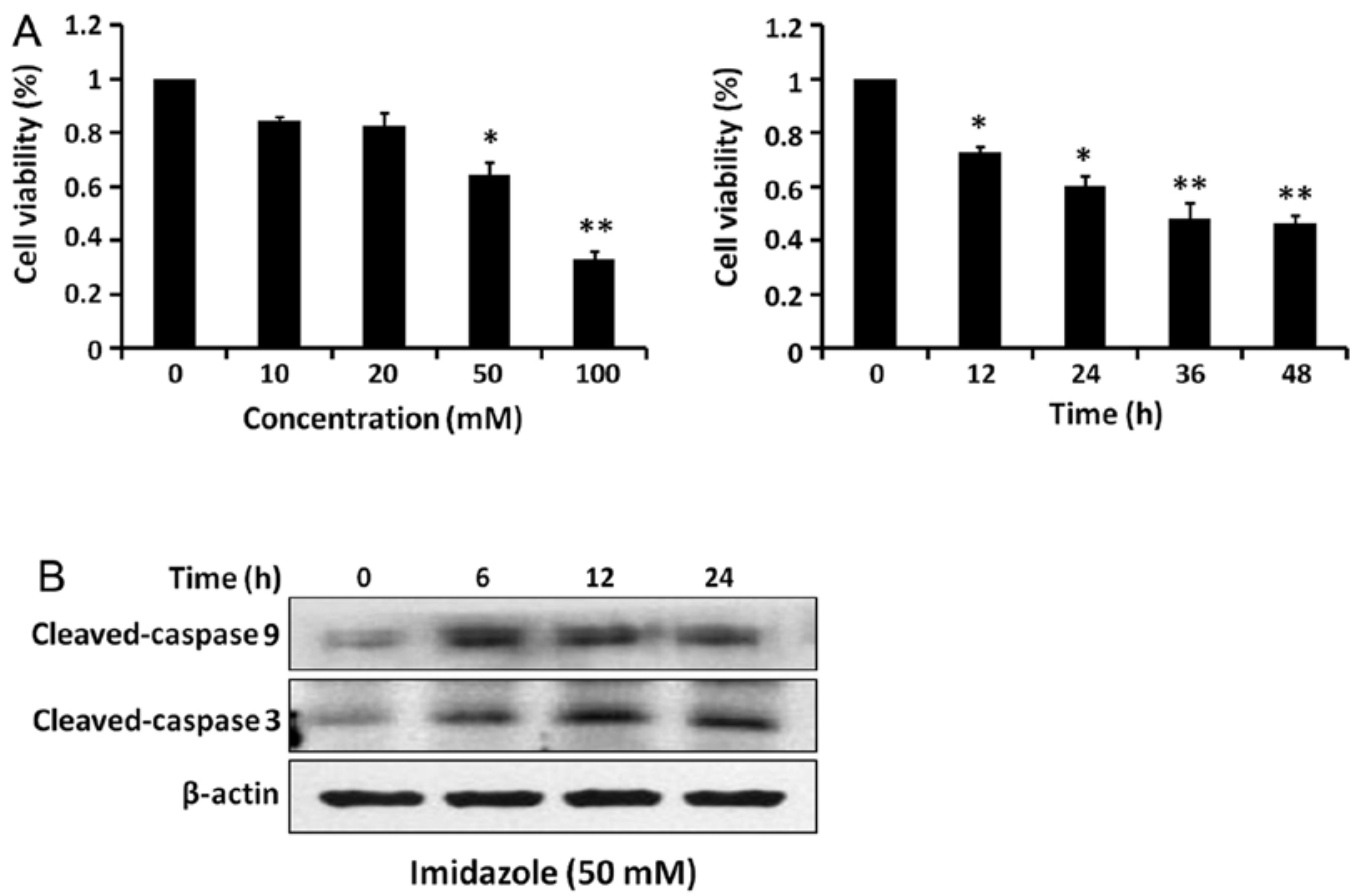

Figure 4. Induction of cell apoptosis by imidazole. (A) Effect of imidazole on cell viability. The HEC-1B cells that were treated with increasing amounts of imidazole $(12 \mathrm{~h})$ or in a certain concentration of imidazole $(50 \mathrm{mM})$ over time were analyzed (MTT assay) for cell viability. The viability of the untreated cells was regarded as $100 \%$. The results from three biological replicates are presented as the means $\pm \mathrm{SD}\left({ }^{*} \mathrm{P}<0.05,{ }^{* * *} \mathrm{P}<0.01\right)$. (B) Activation of caspase 9 and 3 in imidazole-treated cells. Cells treated with or without $50 \mathrm{mM}$ imidazole for indicated intervals were subjected to western blot analysis using antibodies against the cleaved-caspase 3 and cleaved-caspase 9 . $\beta$-actin was used as a loading control. 
A



Imidazole (50 mM)



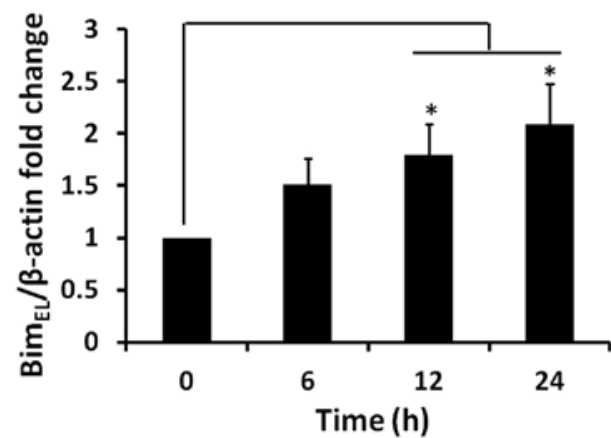

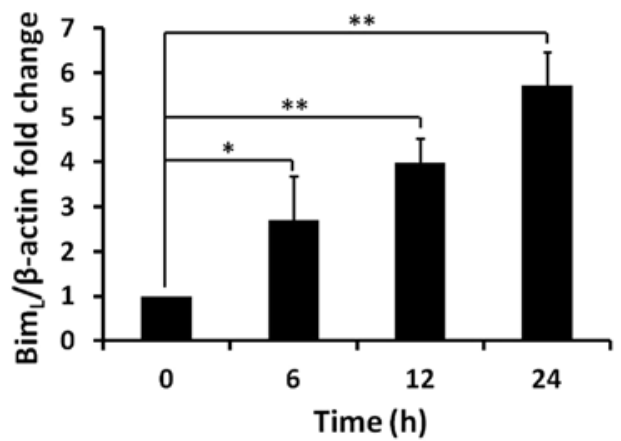

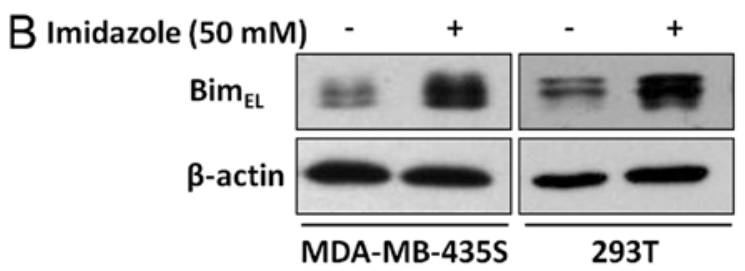

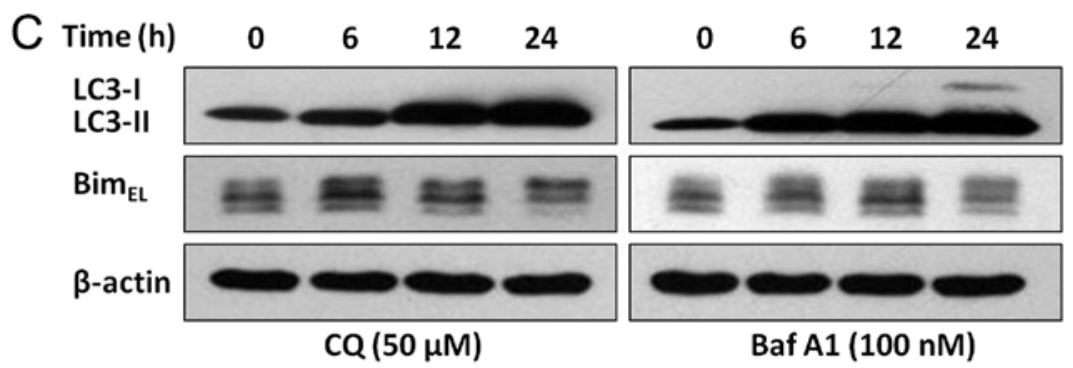

Figure 5. Effects of imidazole on Bim expression. (A) Imidazole upregulated Bim mRNA and protein levels. The HEC-1B cells that were treated with or without imidazole for indicated intervals were analyzed for the Bim mRNA levels by RT-PCR, and GAPDH was used as loading control. Bim EL $_{\text {and Bim }}$ protein expression were examined by western blotting using anti-Bim antibody, and $\beta$-actin was used as loading control. The intensities of western blotting are presented as means \pm SD of three independent experiments. ${ }^{*} \mathrm{P}<0.05,{ }^{* *} \mathrm{P}<0.01$. (B) MDA-MB-435S and $293 \mathrm{~T}$ cell lines were treated with or without imidazole for $12 \mathrm{~h}$, and the abundance of Bim $\mathrm{EL}_{\mathrm{L}}$ was monitored by western blotting. (C) The effects of CQ and Baf A1 on expression of Bim protein. Lysates extracted from cells treated with or without CQ and Baf A1 for indicated intervals were analyzed for the abundance of Bim protein by western blotting.

protein levels in HEC-1B cells (Fig. 6A). Using fluorescence microscopy, the dynamic translocation of FoxO3a-EGFP to the nucleus after imidazole treatment was visualised, whereas FoxO3a-EGFP was located in the cytosol in control cells (Fig. 6B). Further, imidazole treatment for $24 \mathrm{~h}$ increased Bim $_{\mathrm{EL}}$ protein levels in negative control cells, whereas FoxO3a knockdown abrogated the imidazole-induced expression of Bim protein (Fig. 6C). Thus, FoxO3a was involved in regulating the transcription of Bim in imidazole-treated cells. In addition, imidazole-induced cell death was obviously attenuated by siRNA-mediated inhibition of FoxO3a (Fig. 6D). Taken together, we inferred that the transcription factor FoxO3a contributed to the imidazole-induced Bim upregulation and apoptosis in HEC-1B cells.

\section{Discussion}

In this study, we demonstrated that imidazole potently inhibited autophagy by blocking autophagic degradation in HEC-1B cells. Simultaneously, imidazole treatment induced apoptosis in HEC-1B cells by activation of caspase 9 and 3 . The proapoptotic effect was mediated by increased expression of the BH3-only protein Bim. Furthermore, imidazole upregulated the protein level of transcription factor Foxo3a 
A
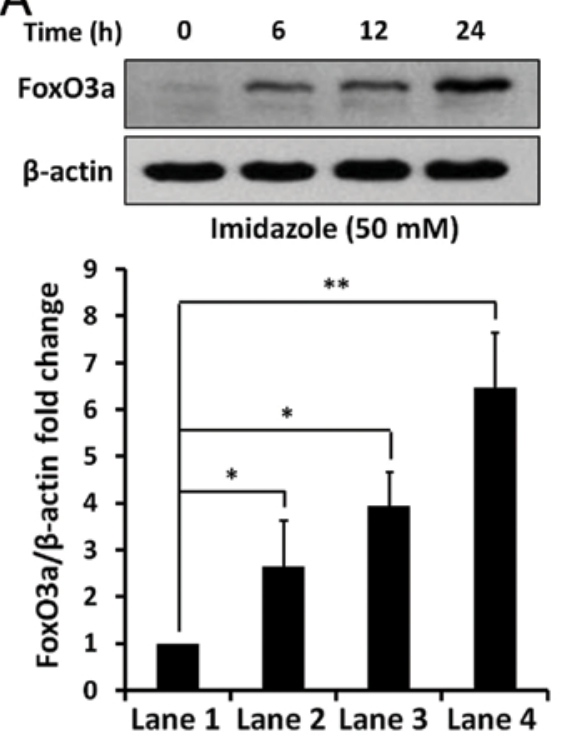

C SIRNA SIRNA SIRNA SiRNA

Imidazole (50 mM) - _ - + + + +
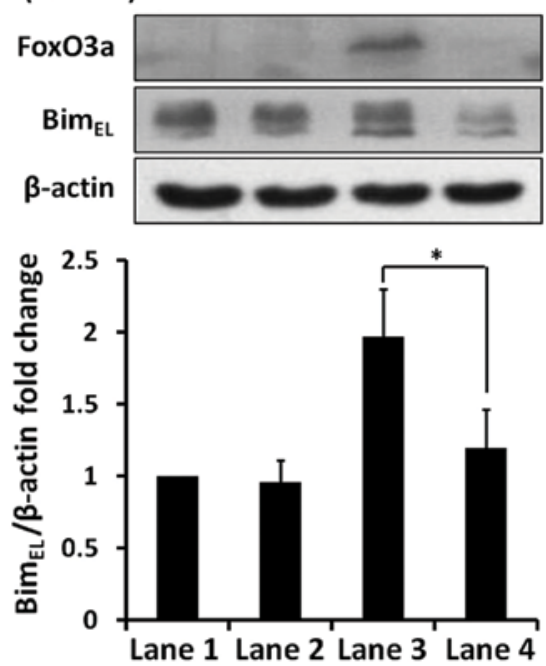

B FoxO3a-EGFP

Hoechst
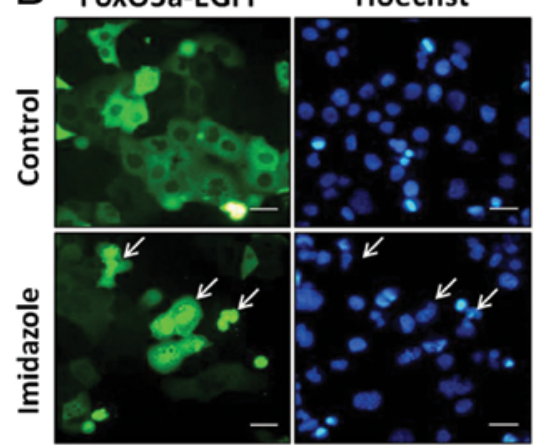

Merge
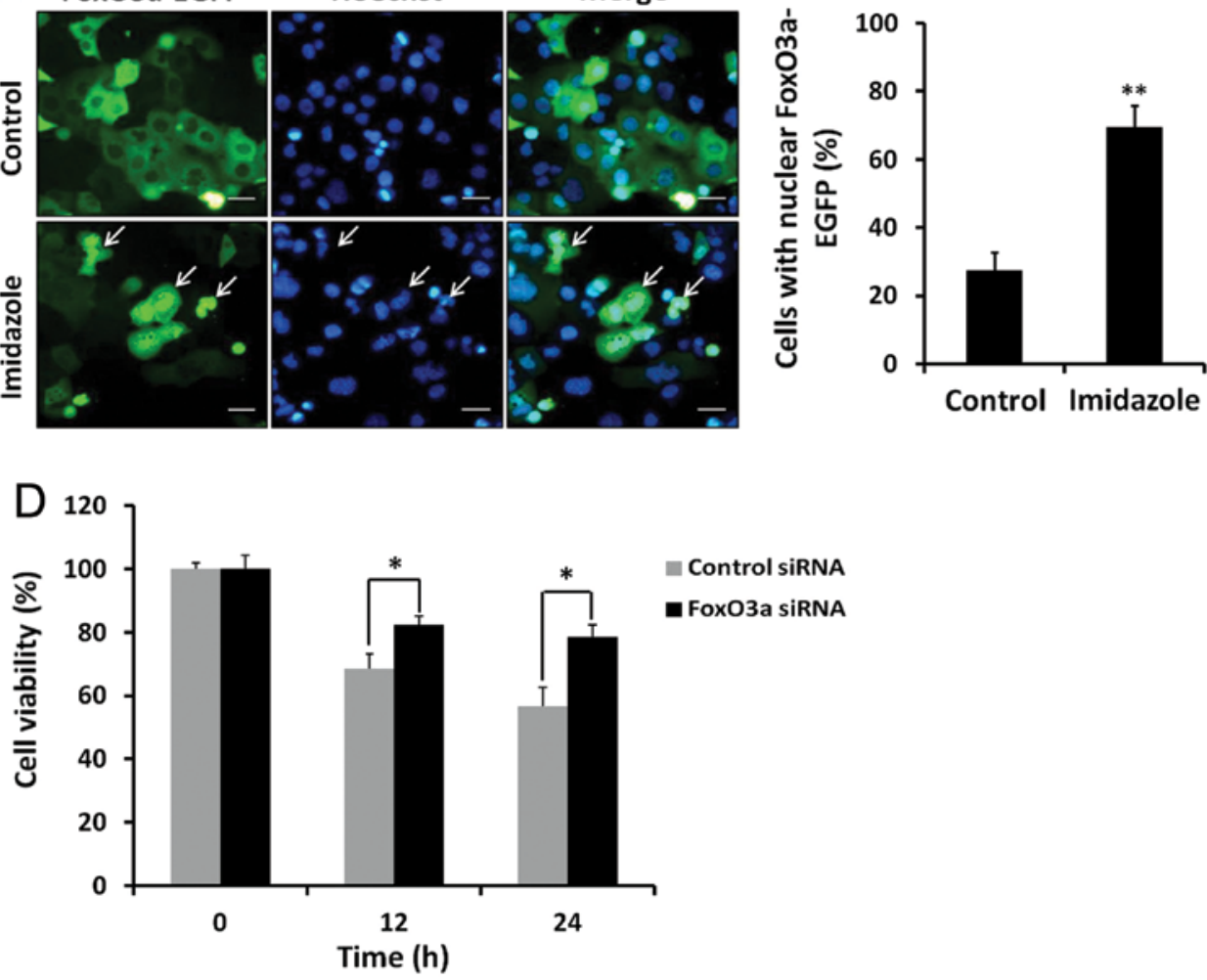

Figure 6. FoxO3a is involved in regulation of Bim expression in imidazole-treated cells. (A) Effects of imidazole on the FoxO3a protein expression. The HEC-1B cells treated with or without imidazole for indicated intervals were examined for the FoxO3a protein levels by western blotting and $\beta$-actin was used as loading control. (B) Analysis of FoxO3a-EGFP nuclear translocation. Cells were transfected with FoxO3a-EGFP vectors and cultured in complete medium with or without $50 \mathrm{mM}$ imidazole for $24 \mathrm{~h}$. The fluorescent signals of FoxO3a-EGFP were sequentially acquired by fluorescence microscopy (x400 magnification). Hoechst staining was used to identify nuclei. Bars, $20 \mu \mathrm{m}$. A total of 100 cells from each group were randomly selected, and cells with nuclear localized FoxO3a-EGFP were counted by ImageJ software. The percentage of cells with nuclear localized FoxO3a-EGFP in the population of 100 cells is shown in the right panel $\left(\mathrm{n}=3,{ }^{* *} \mathrm{P}<0.01\right)$. (C) The effect of FoxO3a knockdown on expression of Bim. Cells that were transfected with negative control siRNA or FoxO3a siRNA for $24 \mathrm{~h}$ were stimulated with or without imidazole for $24 \mathrm{~h}$. The corresponding changes in FoxO3a and Bim protein levels were monitored by western blotting. All results for comparison of the intensities of western blotting were analyzed and were expressed as means \pm SD of three independent experiments. ${ }^{*} \mathrm{P}<0.05$. (D) Effect of FoxO3a silencing on cell viability after imidazole treatment. Cells transfected with negative control siRNA or FoxO3a siRNA were treated with or without $50 \mathrm{mM}$ imidazole for indicated time periods. Cell viability was analyzed by MTT assay. The results from three biological replicates are presented as the means $\pm \mathrm{SD}\left({ }^{*} \mathrm{P}<0.05\right)$.

and induced its increased nuclear localisation. Silencing experiments with FoxO3a siRNA prevented Bim upregulation and cell death.
Autophagy is a cell-survival pathway involving degradation and recycling of long-lived proteins, protein aggregates, damaged cytoplasmic organelles, and intracellular patho- 


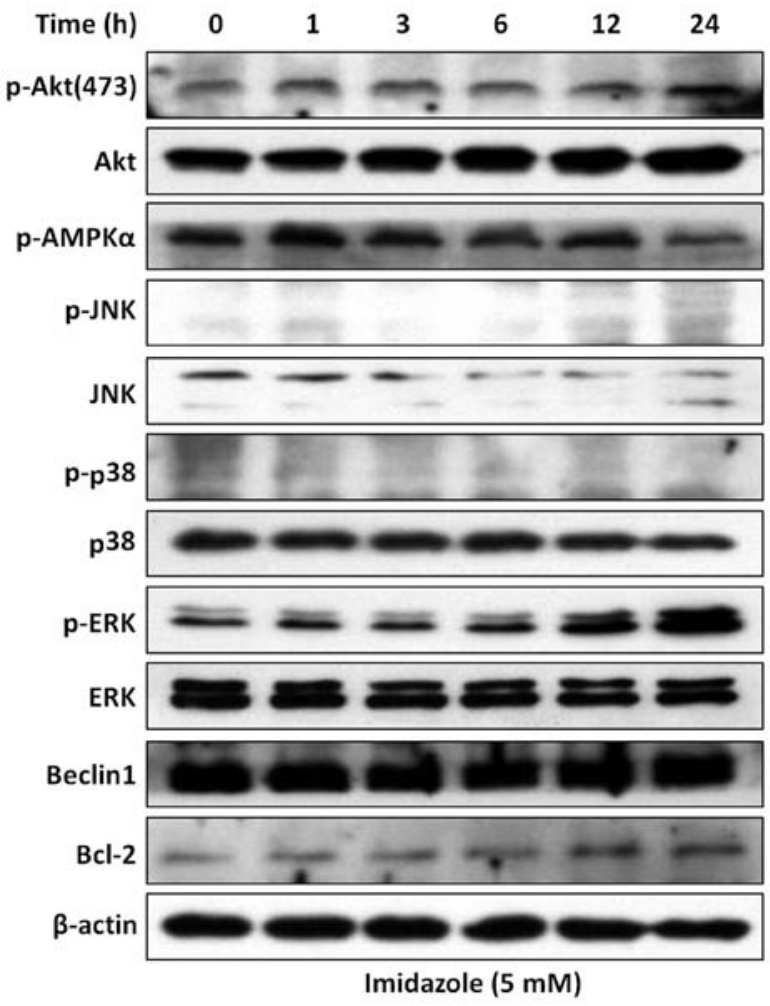

Figure 7. Effects of imidazole on several protein kinases and core molecular proteins. The HEC-1B cells were treated with or without $5 \mathrm{mM}$ imidazole for indicated intervals. Cell lysates were subjected to western blot analysis using corresponding antibodies as shown in the figure. $\beta$-actin was used as a loading control.

gens (9). Normally, it is a tumor suppressor pathway, which may facilitate degradation of oncogenic molecules, thereby preventing development of cancers. However, autophagy appears to have a dual role in cancer, as it also promotes survival of tumor cells under stress conditions, e.g., hypoxic or low-nutrition environments (32). Genetic or pharmacological inhibition of autophagy can increase cancer cellular sensitivity to various anticancer therapies, such as DNA-damaging agents, antihormones and radiation (33). Therefore, inhibition of autophagy is therapeutically beneficial for anticancer treatments. In our experiments, we systematically studied the effects of imidazole on autophagic events in HEC-1B cells; in these studies, the number of AVs was markedly increased in imidazole-treated HEC-1B cells. Based on examination of several endpoints related to the autophagy flux (31), we demonstrated that accumulation of AVs was due to inhibition of autophagic degradation rather than induction of autophagic flux. In addition, several protein kinases and core molecular proteins, required for induction of autophagy such as Akt, AMPK, mitogen-activated protein kinase (ERK, p38 and JNK) (34), Beclin 1 and Bcl-2 (35), were not obviously changed after imidazole treatment (Fig. 7). Although the levels of phosphoERK were increased in response to imidazole treatment, ERK pathway is involved in the control of autophagy process at the maturation step rather than the initiation step (36). These results further supported the concept that imidazole functions as an inhibitor of autophagy by blocking autophagic degradation. Thus, as a potent autophagy inhibitor, imidazole may be expected to have therapeutic effects on cancers with high basal autophagy.

It has been reported that lysosomotropic agents induce accumulation of AVs by blocking autophagic degradation, such as chloroquine (CQ) (37) and matrine (38). They can enter into lysosomes and block trafficking and proteolytic activation of lysosomal proteases. As a weak base, imidazole may enter into acid organelles and alter the intralysosomal $\mathrm{pH}(19,39)$. Thus, we propose that entrapment of imidazole in the lysosomes elevated their $\mathrm{pH}$, which caused lysosome dysfunction and inhibition of autophagic degradation. This conclusion was supported by the important observation that
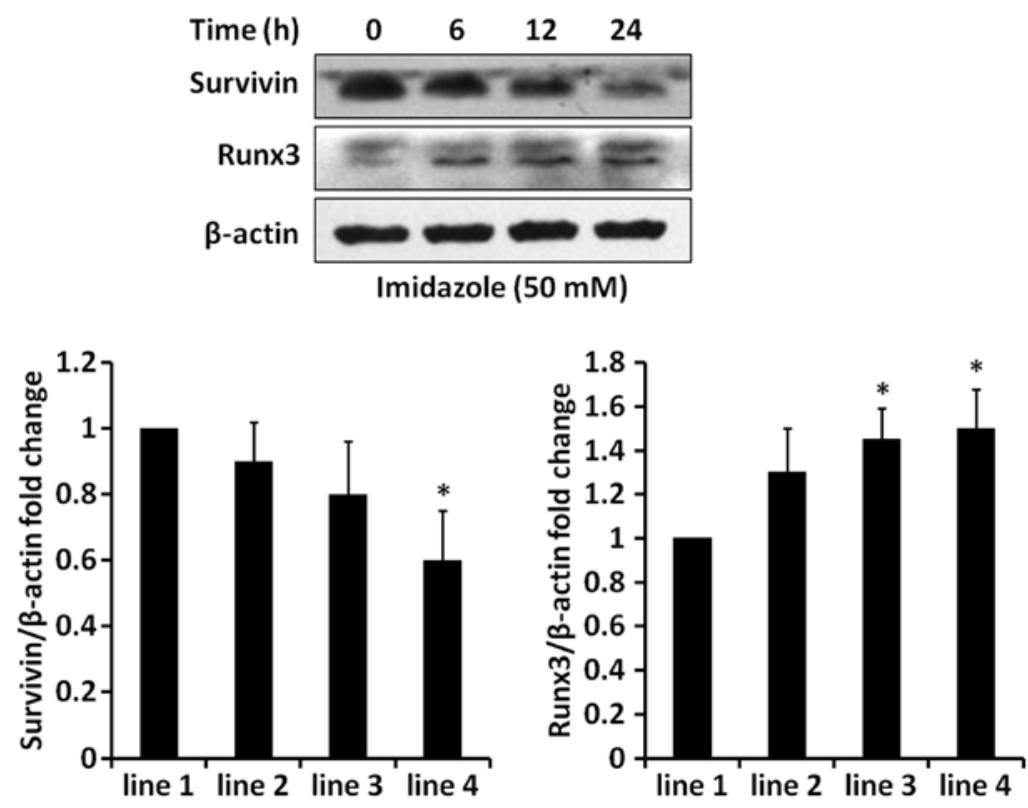

Figure 8. Effects of imidazole on survivin and Runx3 expression. The HEC-1B cells were treated with or without $50 \mathrm{mM}$ imidazole for indicated intervals. Survivin and Runx 3 protein levels were examined by western blotting using anti-survivin and anti-Runx 3 antibodies, and $\beta$-actin was used as loading control. Data for comparison of the intensities of western blotting are represented as means $\pm \mathrm{SD}$ of three independent experiments. ${ }^{*} \mathrm{P}<0.05$. 
the autolysosome maturation, depending on the acidification and degradation capacity of the lysosome, was inhibited after imidazole treatment.

Conversely, it has been reported that imidazole can induce cell apoptosis (29), and its derivatives have anticancer activity in a variety of malignant cells (40). However, the molecular mechanisms underlying imidazole-induced cell apoptosis are not fully elucidated. It is known that $\mathrm{BH} 3$-only protein Bim can trigger cytochrome $c$ release and activation of caspase 9 , which consequentially causes cellular apoptosis (24). In our experiments, imidazole treatment caused HEC-1B cell apoptosis accompanied by the activation of caspase 9 and 3 . Importantly, the pro-apoptotic molecule Bim was obviously increased both at mRNA and protein levels after imidazole treatment. It is well established that Bim has an important role in the anoikis of a variety of cancer cells, such as lung cancer, breast cancer, osteosarcoma and melanoma (26-28). The absence of Bim leads to the occurrence of tumor metastasis and acquisition of chemotherapy resistance (24). Therefore, Bim has attracted increasing attention as a plausible target for tumor therapy. Various chemotherapeutic agents use Bim as a mediating executioner of cell death (e.g., imatinib, gefitinib and bortezomib) (24). Based on the effects of Bim in tumorigenesis and tumor treatment, our findings provided evidence that imidazole may be used as a Bim-targeting agent for tumor therapies in the future, especially tumor metastasis and chemoresistance.

Inhibiting maturation of autolysosome by LAMP-2 knockdown caused accumulation of AVs and subsequent apoptosis in HeLa cells (41). Similarly, hydroxychloroquine, a derivate of $\mathrm{CQ}$, induced AVs accumulation and triggered mitochondriamediated apoptosis in HeLa cells (42). As described above, imidazole treatment also induced accumulation of AVs by blocking autophagic degradation in HEC-B cells. The blockage of autophagic degradation might have triggered the apoptotic procedure by upregulation of Bim. In this study, two kinds of autophagy inhibitors $\mathrm{CQ}$ and Baf A1, both known to inhibit autophagic degradation $(37,43)$, were used to investigate the role of blockage of autophagic degradation in the regulation of Bim expression. We observed that there were no significant changes in the Bim protein levels after CQ or Baf A1 treatment in HEC-1B cells. Therefore, we inferred that imidazoleinduced Bim expression was independent of the blockage of autophagic degradation. Furthermore, the reciprocal influence of AVs accumulation and apoptotic cell death still require further investigation.

The pro-apoptotic activity of Bim is tightly controlled by transcriptional and post-transcriptional systems (24). The forkhead-like transcription factor FoxO3a (forkhead box O3a) is a key transcriptional regulator of Bim (44). Cytokine withdrawal or apoptotic stimuli cause upregulation of Bim through activation of FoxO3a in various cell types, including osteoblasts, hepatocytes and neurons (45-47). It has been demonstrated that the FoxO3a-Bim pathway participates in apoptotic processes in response to many chemotherapeutic agents. For example, paclitaxel can induce Bim $\mathrm{EL}_{\mathrm{EL}}$ expression and subsequently cell apoptosis via increasing FoxO3a expression in MCF-7 breast cancer cells (48). Similarly, melatonin can induce apoptosis in HepG2 hepatocarcinoma cells through the upregulation of Bim mediated by nuclear translocation and activation of the transcription factor FoxO3a (49). In the present study, imidazole upregulated the protein level of Foxo3a and induced its increased nuclear localisation, suggesting a possible association between FoxO3a as a transcription factor of Bim in HEC-1B cells. Furthermore, FoxO3a accumulation and Bim protein expression were greatly reduced upon silencing of FoxO3a by siRNA, validating that FoxO3a functions as a transcriptional regulator of Bim expression after imidazole treatment. Moreover, depletion of FoxO3a by siRNA significantly reduced imidazole-mediated cell death. Therefore, our findings provide evidence that FoxO3a-Bim pathway has a critical role in imidazole-induced apoptosis in HEC-1B cells. However, the knockdown of FoxO3a did not completely abolish imidazole-induced cell death. Perhaps imidazole might induce other mechanisms to promote apoptosis in HEC-1B cells. Indeed, we also observed that imidazole treatment caused an obvious change in several apoptosis-related molecules, e.g., tumor suppressor Runx3 and anti-apoptotic protein survivin (Fig. 8). These changes of apoptosis-related molecules probably contributed to imidazole-induced cell death.

In conclusion, this is the first report that imidazole is a potent inhibitor of autophagy flux by blocking autophagic degradation; simultaneously, imidazole induced apoptosis by FoxO3a-Bim pathway in HEC-1B cells. Our data provided a molecular link between imidazole drugs and anticancer therapies. These findings could be an important advance for understanding the oncostatic effects of imidazoles in vitro; however, additional studies are required to further elucidate the therapeutic value and clinical applications of imidazole compounds.

\section{Acknowledgements}

We thank Dr John P. Kastelic of the University of Calgary for useful discussion and suggestions on this investigation. This study was supported by the National Science \& Technology Pillar Program during the 12th Five-year Plan Period (2012BAI32B05).

\section{References}

1. Grassmann S, Sadek B, Ligneau X, et al: Progress in the proxifan class: heterocyclic congeners as novel potent and selective histamine H(3)-receptor antagonists. Eur J Pharm Sci 15: 367-378, 2002.

2. Labanauskas L, Brukstus A, UdrenaiteE, Gaidelis P,Bucinskaite V and Dauksas V: Synthesis of 6,7-dialkoxy-2-arylmethylidene-2,3dihydrobenzo[4,5]imidazo[2,1-b][1,3]thiazol-3-ones exhibiting anti-inflammatory activity. Pharmazie 55: 429-431, 2000.

3. Sevak R, Paul A, Goswami S and Santani D: Gastroprotective effect of beta3 adrenoreceptor agonists ZD 7114 and CGP 12177A in rats. Pharmacol Res 46: 351-356, 2002.

4. Can-Eke B, Puskullu MO, Buyukbingol E and Iscan M: A study on the antioxidant capacities of some benzimidazoles in rat tissues. Chem Biol Interact 113: 65-77, 1998.

5. Hoskin PJ, Saunders MI and Dische S: Hypoxic radiosensitizers in radical radiotherapy for patients with bladder carcinoma: hyperbaric oxygen, misonidazole, and accelerated radiotherapy, carbogen, and nicotinamide. Cancer 86: 1322-1328, 1999.

6. Brown JM: The hypoxic cell: a target for selective cancer therapy - eighteenth Bruce F. Cain Memorial Award lecture. Cancer Res 59: 5863-5870, 1999.

7. Baviskar AT, Madaan C, Preet R, et al: N-fused imidazoles as novel anticancer agents that inhibit catalytic activity of topoisomerase IIalpha and induce apoptosis in G1/S phase. J Med Chem 54: 5013-5030, 2011. 
8. Gunther W, Pawlak E, Damasceno R, Arnold H and Terzis AJ: Temozolomide induces apoptosis and senescence in glioma cells cultured as multicellular spheroids. Br J Cancer 88: 463-469, 2003.

9. Levine B and Klionsky DJ: Development by self-digestion: molecular mechanisms and biological functions of autophagy. Dev Cell 6: 463-477, 2004.

10. Mizushima N, Levine B, Cuervo AM and Klionsky DJ: Autophagy fights disease through cellular self-digestion. Nature 451: 1069-1075, 2008 .

11. Rubinsztein DC, Gestwicki JE, Murphy LO and Klionsky DJ: Potential therapeutic applications of autophagy. Nat Rev Drug Discov 6: 304-312, 2007.

12. Lum JJ, Bauer DE, Kong M, et al: Growth factor regulation of autophagy and cell survival in the absence of apoptosis. Cell 120 237-248, 2005 .

13. Degenhardt K, Mathew R, Beaudoin B, et al: Autophagy promotes tumor cell survival and restricts necrosis, inflammation, and tumorigenesis. Cancer Cell 10: 51-64, 2006

14. Paglin S, Hollister T, Delohery T, et al: A novel response of cancer cells to radiation involves autophagy and formation of acidic vesicles. Cancer Res 61: 439-444, 2001.

15. Kanzawa T, Germano IM, Komata T, Ito H, Kondo $\mathrm{Y}$ and Kondo S: Role of autophagy in temozolomide-induced cytotoxicity for malignant glioma cells. Cell Death Differ 11: 448-457, 2004.

16. Gorka M, Daniewski WM, Gajkowska B, Lusakowska E, Godlewski MM and Motyl T: Autophagy is the dominant type of programmed cell death in breast cancer MCF-7 cells exposed to AGS 115 and EFDAC, new sesquiterpene analogs of paclitaxel. Anticancer Drugs 16: 777-788, 2005.

17. Apel A, Herr I, Schwarz H, Rodemann HP and Mayer A: Blocked autophagy sensitizes resistant carcinoma cells to radiation therapy. Cancer Res 68: 1485-1494, 2008.

18. Mizushima N: Autophagy: process and function. Genes Dev 21: 2861-2873, 2007.

19. Ohkuma S and Poole B: Cytoplasmic vacuolation of mouse peritoneal macrophages and the uptake into lysosomes of weakly basic substances. J Cell Biol 90: 656-664, 1981.

20. Cotter TG: Apoptosis and cancer: the genesis of a research field. Nat Rev Cancer 9: 501-507, 2009.

21. Bold RJ, Termuhlen PM and McConkey DJ: Apoptosis, cancer and cancer therapy. Surg Oncol 6: 133-142, 1997.

22. Strasser A: The role of $\mathrm{BH} 3$-only proteins in the immune system. Nat Rev Immunol 5: 189-200, 2005.

23. Bouillet P and Strasser A: BH3-only proteins - evolutionarily conserved proapoptotic Bcl-2 family members essential for initiating programmed cell death. J Cell Sci 115: 1567-1574, 2002.

24. Akiyama T, Dass CR and Choong PF: Bim-targeted cancer therapy: a link between drug action and underlying molecular changes. Mol Cancer Ther 8: 3173-3180, 2009.

25. Ren D, Tu HC, Kim H, et al: BID, BIM, and PUMA are essential for activation of the BAX- and BAK-dependent cell death program. Science 330: 1390-1393, 2010.

26. Simpson CD, Anyiwe $\mathrm{K}$ and Schimmer AD: Anoikis resistance and tumor metastasis. Cancer Lett 272: 177-185, 2008.

27. Uehara N, Matsuoka Y and Tsubura A: Mesothelin promotes anchorage-independent growth and prevents anoikis via extracellular signal-regulated kinase signaling pathway in human breast cancer cells. Mol Cancer Res 6: 186-193, 2008.

28. Woods NT, Yamaguchi H, Lee FY, Bhalla KN and Wang HG: Anoikis, initiated by Mcl-1 degradation and Bim induction, is deregulated during oncogenesis. Cancer Res 67: 10744-10752, 2007 .
29. Iguchi K, Usui S, Ishida R and Hirano K: Imidazole-induced cell death, associated with intracellular acidification, caspase-3 activation, DFF-45 cleavage, but not oligonucleosomal DNA fragmentation. Apoptosis 7: 519-525, 2002.

30. Denizot F and Lang R: Rapid colorimetric assay for cell growth and survival. Modifications to the tetrazolium dye procedure giving improved sensitivity and reliability. J Immunol Methods 89: 271-277, 1986

31. Mizushima N, Yoshimori $\mathrm{T}$ and Levine B: Methods in mammalian autophagy research. Cell 140: 313-326, 2010.

32. Su M, Mei Y and Sinha S: Role of the crosstalk between autophagy and apoptosis in cancer. J Oncol 2013: 102735, 2013.

33. Yang ZJ, Chee CE, Huang S and Sinicrope FA: The role of autophagy in cancer: therapeutic implications. Mol Cancer Ther 10: 1533-1541, 2011

34. Sridharan S, Jain K and Basu A: Regulation of autophagy by kinases. Cancers (Basel) 3: 2630-2654, 2011.

35. Sinha $S$ and Levine B: The autophagy effector Beclin 1: a novel BH3-only protein. Oncogene 27 (Suppl 1): S137-S148, 2008.

36. Corcelle E, Djerbi N, Mari M, et al: Control of the autophagy maturation step by the MAPK ERK and p38: lessons from environmental carcinogens. Autophagy 3: 57-59, 2007.

37. Geng Y, Kohli L, Klocke BJ and Roth KA: Chloroquine-induced autophagic vacuole accumulation and cell death in glioma cells is p53 independent. Neuro Oncol 12: 473-481, 2010.

38. Wang Z, Zhang J, Wang Y, et al: Matrine, a novel autophagy inhibitor, blocks trafficking and the proteolytic activation of lysosomal proteases. Carcinogenesis 34: 128-138, 2013.

39. Poole B and Ohkuma S: Effect of weak bases on the intralysosomal $\mathrm{pH}$ in mouse peritoneal macrophages. J Cell Biol 90 665-669, 1981.

40. Krezel I: New derivatives of imidazole as potential anticancer agents. Farmaco 53: 342-345, 1998.

41. Gonzalez-Polo RA, Boya P, Pauleau AL, et al: The apoptosis/ autophagy paradox: autophagic vacuolization before apoptotic death. J Cell Sci 118: 3091-3102, 2005.

42. Boya P, Gonzalez-Polo RA, Casares N, et al: Inhibition of macroautophagy triggers apoptosis. Mol Cell Biol 25: 1025-1040, 2005.

43. Yamamoto A, Tagawa Y, Yoshimori T, Moriyama Y, Masaki R and Tashiro Y: Bafilomycin A1 prevents maturation of autophagic vacuoles by inhibiting fusion between autophagosomes and lysosomes in rat hepatoma cell line, H-4-II-E cells. Cell Struct Funct 23: 33-42, 1998

44. Zanella F, Link W and Carnero A: Understanding FOXO, new views on old transcription factors. Curr Cancer Drug Targets 10: 135-146, 2010.

45. Kawamura N, Kugimiya F, Oshima Y, et al: Akt1 in osteoblasts and osteoclasts controls bone remodeling. PLoS One 2: e1058, 2007.

46. Barreyro FJ, Kobayashi S, Bronk SF, Werneburg NW, Malhi $\mathrm{H}$ and Gores GJ: Transcriptional regulation of Bim by FoxO3A mediates hepatocyte lipoapoptosis. J Biol Chem 282: 27141-27154, 2007

47. Gilley J, Coffer PJ and Ham J: FOXO transcription factors directly activate bim gene expression and promote apoptosis in sympathetic neurons. J Cell Biol 162: 613-622, 2003.

48. Sunters A, Fernandez de Mattos S, Stahl M, et al: FoxO3a transcriptional regulation of Bim controls apoptosis in paclitaxeltreated breast cancer cell lines. J Biol Chem 278: 49795-49805, 2003.

49. Carbajo-Pescador S, Steinmetz C, Kashyap A, et al: Melatonin induces transcriptional regulation of Bim by FoxO3a in HepG2 cells. Br J Cancer 108: 442-449, 2013. 